\title{
Síndromes paraneoplásicas - o que o cirurgião-dentista precisa saber?
}

\section{Paraneoplastic syndromes - what does the surgeon-dentist needs to know?}

\begin{abstract}
RESUMO
Introdução: o termo paraneoplasia é um conjunto de distúrbios clínicos, bioquímicos, hormonais, neurológicos e/ou hematológicos associados com neoplasias malignas, mas não diretamente relacionados com invasão tumoral primária ou metástase. As síndromes paraneoplásicas podem ser o primeiro sinal de uma malignidade.
\end{abstract}

Revisão de literatura: as síndromes que estão mais comumente relacionadas com a prática odontológica são: de Lambertt-Eaton, de Gardner, de Cowden, de Peutz-Jeghers, de Sjögren, a neoplasia endócrina múltipla, a neurofibromatose múltipla de Von Recklinghausen, o carcinoma nevóide de células basais, a acantose nigrans e o pênfigo paraneoplásico.

Conclusão: o diagnóstico precoce das neoplasias malignas favorece o seu prognóstico e as síndromes paraneoplásicas auxiliam neste diagnóstico. É de suma importância que os Cirurgiões-dentistas conheçam tais síndromes de modo a diagnosticá-las o mais rápido possível e encaminhar os pacientes ao tratamento especializado.

Palavras-chave: Síndromes Paraneoplásicas; Diagnóstico Precoce; Tratamento.

\begin{abstract}
Introduction: the term paraneoplastic is a clinical, biochemical, hormonal, neurological and/or associated disorder with hematologic malignancies, but not directly related to primary tumor invasion and metastasis. Paraneoplatic syndromes may be the first sign of a malignancy.
\end{abstract}

Review of literature: the syndromes that are most commonly related to dentistry are of lambertt-Eaton, Gardner, Cowden disease, Peutz-Jeghers, Sjögren, multiple endocrine neoplasic, multiple neurofibromatosis of Von Recklinghausen, nevoid basal cell carcinoma, acanthosis nigrans and pemphigus paraneoplastic.

Conclusion: early diagnosis of malignant neoplasms favors prognosis and paraneoplastic syndromes assist in diagnosis. It is important that surgeons-dentists know these events in order to diagnose them as soon as possible and refer these patients to specialized treatment.

Keywords: Paraneoplastic Syndromes; Early Diagnosis; Treatment.

\author{
Marceli Moço Silva* \\ Marcelo Macedo Crivelini** \\ Norberto Perri Moraes*** \\ João Paulo De Carli**** \\ Soluete Oliveira da Silva***** \\ Maria Salete Sandini Linden***** \\ Glauco Issamu Miyahara*******
}

* Aluna do curso de doutorado do programa de pós-graduação em odontologia, área de concentração Estomatologia, da Faculdade de Odontologia de Araçatuba-UNESP.

** Professor Adjunto da disciplina de Patologia do Departamento de Patologia e Propedêutica Clínica da Faculdade de Odontologia de Araçatuba-UNESP.

*** Professor Titular da Disciplina de Estomatologia do Departamento de Patologia e Propedêutica Clínica da Faculdade de Odontologia de Araçatuba - UNESP.

**** Aluno do curso de doutorado em Estomatologia da Pontifícia Universidade Católica do Paraná. Professor Assistente da Faculdade de Odontologia da Universidade de Passo Fundo.

***** Doutora em Estomatologia Clínica, Professora Titular da Faculdade de Odontologia da Universidade de Passo Fundo.

****** Doutora em Implantodontia, Professora Titular da Faculdade de Odontologia da Universidade de Passo Fundo.

****** Professor Adjunto da Disciplina de Estomatologia do Departamento de Patologia e Propedêutica Clínica da Faculdade de Odontologia de Araçatuba - UNESP.

Endereço para correspondência: Marceli Moço Silva

Av. Santo Antonio, 321, Centro,

Adamantina - SP CEP: 17800-000

Enviado: 7/12/2009.

Aceito: 2/3/2010. 


\section{INTRODUÇÃO}

As manifestações clínicas do câncer são em geral causadas pelos efeitos locais do crescimento do tumor no sitio primário ou são inespecíficas, como anorexia, mal estar, perda de peso, sudorese noturna e febre. $\mathrm{O}$ termo paraneoplasia é um conjunto de distúrbios clínicos, bioquímicos, hormonais, neurológicos e/ou hematológicos associados com neoplasias malignas, mas não diretamente relacionados com invasão tumoral primária ou metástase. As síndromes paraneoplásicas podem ser o primeiro sinal de uma malignidade e podem afetar até $15 \%$ dos pacientes portadores de câncer ${ }^{1-2}$.

Até dois terços das síndromes paraneoplásicas podem estar associadas a tumores relativamente pequenos. $\mathrm{O}$ reconhecimento destas associações levam a um diagnóstico precoce e consequentemente a um melhor tratamento. O tratamento eficaz e efetivo da malignidade subjacente está acompanhado pela melhora ou resolução da síndrome, uma vez que a evolução desta geralmente é paralela à evolução do tumor. A síndrome muitas vezes pode constituir um risco de morte maior e mais rápido do que o próprio câncer ${ }^{3}$.

Estas síndromes podem ser causadas por uma variedade de mecanismos, como secreção de proteínas que não estão associadas com o equivalente normal do câncer (síndromes endócrinas ectópicas, destruição total dos tecidos pelas citocinas secretadas pelos tumores); anticorpos específicos contra antígenos que normalmente se expressam em outros tecidos (síndromes neurológicas); efeitos devidos a mecanismos desconhecidos como produtos do tumor não identificados ou complexos imunes simulados pelo tumor (osteoartropatia causada pelo carcinoma broncogênico). Mesmo sintomas inespecíficos como febre e perda de peso são realmente paraneoplásicos e são devidos à produção de fatores específicos (fator de necrose tumoral), ou à reação das células normais em relação ao tumor ${ }^{3}$.

O câncer mais comum associado à síndrome paraneoplásica é o carcinoma de pulmão de pequenas células, provavelmente devido a sua origem neuroectodérmica. Outros tumores comumente associados à síndrome incluem os carcinomas de mama, ovário e doenças linfoproliferativas (especialmente a doença de Hodgkin) ${ }^{2}$.

Diante disto, é de grande importância clínica, por parte do Cirurgiãodentista, obter informações a respeito das síndromes paraneoplásicas de interesse na odontologia, de modo a identificar elementos que possam ajudar no diagnóstico precoce dessas neoplasias malignas. Com intuito de um melhor entendimento destas síndromes, didaticamente, as mesmas são divididas em: síndrome neurológica paraneoplásica, síndrome dermatológica paraneoplásica, lesões cutâneas associadas com doença maligna, síndrome reumatológica paraneoplásica, e síndrome hematológica paraneoplásica.

\section{Síndrome neurológica paraneoplásica}

A sindrome da miastenia de Lambertt-Eaton (anticorpo anti-VGCC) afeta de 1 a $2 \%$ dos pacientes com carcinoma de pulmão de pequenas células e 
dois terços dos casos estão associados com uma malignidade subjacente. Clinicamente, os pacientes apresentam fraqueza da extremidade inferior com aumento da força depois de diversos segundos de contração voluntária mantida, sendo que ptose e impotência sexual também podem acontecer. O sinal odontológico mais comum é a xerostomia ou boca seca. A síndrome está associada com defeito na liberação dos neurotransmissores (acetilcolina) dos neurônios pré-sinápticos na junção neuromuscular e em outros locais. A liberação da acetilcolina é mediada pelo canal de cálcio dependente de voltagem (VGCCs). O diagnóstico é realizado por meio do exame de sangue, sendo que os anticorpos anti-VGCC são encontrados no soro de mais de $85 \%$ dos pacientes com a síndrome ${ }^{2}$. O tratamento consiste em associação de plasmaférese, imunoglobulina intravenosa para ligar os anticorpos circulantes e imunossupressão (para remover os anticorpos e suprimir sua produção), assim como o tratamento da malignidade subjacente ${ }^{4}$.

\section{Síndrome dermatológica paraneoplásica}

A seguir são apresentadas síndromes genéticas com manifestações cutâneas com um maior risco de tumores sistêmicos.

A síndrome de Gardner clinicamente apresenta lesões cutâneas como cistos sebáceos epidérmicos múltiplos da face e do couro cabeludo, tumores cutâneos dermóides, dentes supranumerários, osteomas da face e cabeça, além de pólipos gastrintestinais. Os osteomas antecedem o aparecimento dos pólipos gastrintestinais. Aos 30 anos, 50\% dos pacientes com a síndrome de Gardner desenvolvem neoplasias malignas gastrintestinais, e aos 50 anos, quase $100 \%$. É uma enfermidade autossômica dominante, sendo que o defeito genético se localiza no gene APC (adenomatous polyposis coli) situado no braço longo do cromossomo 5q21. Em aproximadamente $20 \%$ dos casos, a doença pode ser decorrente de mutações genéticas. $\mathrm{O}$ tratamento consiste em remoção das manifestações clínicas apresentadas pela síndrome, como remoção dos osteomas e remoção total do intestino preventivamente ${ }^{6}$.

A sindrome de Cowden é uma enfermidade autossômica dominante, sendo que a mutação ocorre no gene PTEN (fosfatase e tensina homólogas deletadas no cromossomo 10) ${ }^{7}$. Apresenta hamartomas múltiplos da pele e membranas mucosas (triquilenomas), além de lipomas por todo o corpo e mucosas. As lesões mucocutâneas são as mais representativas da doença e consistem em: pápulas liquenóides achatadas da cor da pele normal de distribuição centrofacial com tendência ao agrupamento ao redor dos olhos, nariz e boca. Notam-se também pápulas achatadas hiperqueratóticas semelhantes a verrugas planas no dorso das mãos e punhos que não aparecem no dorso dos pés, além de queratoses translucentes nas palmas, plantas e face lateral de mãos e pés. Os tumores associados são neoplasias malignas de mama e tireóide ${ }^{8}$.

Os papilomas bucais típicos usualmente têm entre um e três mm na maior extensão e afetam as gengivas, o dorso da língua, a mucosa bucal, o palato, o rebordo alveolar e a fossa tonsilar, assumindo com frequência aspecto semelhante ao de "pedras arredondadas". O quadro histológico 
das lesões bucais é bastante inespecífico, representando essencialmente hiperplasia fibroepitelial. O diagnóstico é clínico e o tratamento consiste em remoção das manifestações clínicas apresentadas pela síndrome, bem como tratamento da malignidade ${ }^{9}$.

A sindrome Men IIB (multiple endocrine neoplasia ou neoplasia endocrina multipla) apresenta múltiplos neuromas em pele e mucosa, mucosas papulares, principalmente em lábios, orofaringe e conjuntiva. A neoplasia endócrina múltipla tipo-2 (NEM-2) é herdada por genes autossômicos dominantes e compreende um grupo de doenças, tais como carcinoma medular de tireóide familiar (CMT-F), neoplasia endócrina múltipla tipo-2A (NEM-2A), que apresenta CMT associado à feocromocitoma (FEO) e hiperparatireoidismo primário (HPT), e NEM, tipo-2B (NEM-2B), onde ocorrem CMT, FEO e gânglio-neuromatose de mucosas $^{10}$. Em 1993, foi identificado o proto-oncogene RET como gene responsável pela NEM 2. O proto-oncogene $R E T$ apresenta 21 exons e codifica um receptor tirosino-quinase expresso nas células derivadas da crista neural, incluindo tumores neuroendócrinos originados dessas células. O ligante do RET foi identificado em 1996 e é um peptídeo da superfamília do TGF-b (transforming growth factor) ${ }^{11}$.

A neurofibromatose múltipla de Von Recklinghausen apresenta manchas café com leite, sardas axilares, feocromocitoma, neuromas acústicos e neurofibromas, sendo que de 5 a 15\% destes neurofibromas se transformam em neurofibrossarcoma. A neurofibromatose pode ser dividida em dois tipos: tipo 1 (periférica) e tipo 2 (central). Recentemente, verificou-se que em ambos os tipos o gene anormal localiza-se no braço longo do cromossomo 17 (17q11.2) $)^{12-13}$, que é responsável por uma proteína (neurofibromina) ${ }^{12}$.

A sindrome de Peutz-Jeghers apresenta máculas pigmentadas nos lábios, mucosa bucal, mãos e pés, além de pólipos gastrintestinal hamartomatosos. Os tumores associados são tumores gastrintestinais, de pâncreas, ovário e testículo. Ao exame clínico odontológico, o Cirurgião-dentista pode suspeitar que o paciente seja portador desta síndrome por meio dessas manchas na mucosa bucal e encaminhar ao geneticista para a confirmação do diagnóstico. Posteriormente, o paciente deve ser encaminhado ao médico clínico para acompanhar a possível formação de pólipos gastrintestinais, que têm a sua remoção como tratamento. A etiologia está associada com o gene causal no cromossomo $19 \mathrm{p} 13^{14}$.

A sindrome do carcinoma nevóide de células basais ou síndrome de Gorlin apresenta tumores basocelulares múltiplos, alterações esqueléticas (costela bífida, ossos frontal e parietal aumentados e prognatismo mandibular), tumor odontogênico queratocístico, anormalidades cutâneas, retardo mental, estrabismo e calcificação cerebral. Os tumores associados são meduloblastoma e fibrossarcoma. Ao exame clínico odontológico, normalmente o Cirurgião-dentista suspeita que o paciente seja portador desta síndrome por meio da presença dos tumores basocelulares e queratocistos odontogênicos, sendo o tratamento a remoção dessas manifestações. $\mathrm{O}$ gene PTCH que é um gene supressor de tumor, se localiza no cromossomo 9 e seria o responsável por esta síndrome ${ }^{15-17}$. 


\section{Lesões cutâneas associadas com doença maligna}

A acantose nigrans se manifesta como hiperpigmentação aveludada e verrucosa no pescoço, axila, virilhas e membranas mucosas. Quando se apresenta na boca está associada com malignidades gastrintestinais. Em relação às hiperpigmentações na boca, esta enfermidade é considerada uma condição pré-maligna, ou seja, se no momento não é, certamente se tornará uma lesão maligna com o passar do tempo. A sua patogênese não está totalmente esclarecida, apesar de citocinas e resistência à insulina terem sido implicadas (fator de transformação de crescimento TGF $-\alpha)^{18}$.

O pênfigo paraneoplásico caracteriza-se por lesões vesiculares e ulcerativas na boca e pele, associadas a linfoma, outras doenças linfoproliferativas e tumores do timo. Os pacientes apresentam altos títulos de auto-anticorpos que reagem contra os antígenos do tumor, ocorrendo também reação cruzada com antígenos na junção das células epidérmicas. A coloração pela imunofluorescência indireta mostra uma deposição de auto-anticorpos de imunoglobulinas $\mathrm{G}$ na superfície das células epidérmicas ${ }^{1}$.

\section{Síndrome reumatológica paraneoplásica}

A sindrome de Sjögren é caracterizada por xerostomia (boca seca), xeroftalmia (conjuntiva ocular seca) e artrite, sendo que os portadores apresentam risco ligeiramente aumentado de doença linfoproliferativa ${ }^{19}$. O Cirurgião-dentista pode suspeitar que o paciente seja portador desta síndrome por meio da presença da xerostomia bastante evidente. A biópsia de uma glândula salivar menor, associada com as outras características da tríade, é necessária para a confirmação do diagnóstico. Ao exame histológico desta glândula salivar se observa uma inflamação nos ductos da mesma. É recomendado encaminhar o paciente ao reumatologista para acompanhar e tratar os sintomas desta síndrome.

\section{Síndrome hematológica paraneoplásica}

O Cirurgião-dentista precisa ficar atento a sangramentos gengivais e ulcerações na mucosa bucal sem causa evidente, como placa e cálculos dentais, ou ainda traumas. Não evidenciando a causa de tais sangramentos, é necessária uma avaliação sistêmica com exames complementares, como hemograma, coagulograma e encaminhamento ao hematologista.

Outras características importantes incluem a febre sem infecções evidentes, bem como a caquexia, que é caracterizada por anorexia, perda de tecido subcutâneo e cansaço. A caquexia parece ser causada por uma combinação de consumo protéico, má absorção, desregulação imune e aumento do ciclo da glicose conseqüente ao aumento do consumo induzido do tumor.

\section{CONCLUSÃO}

- o diagnóstico precoce das neoplasias malignas, auxiliado pelas síndromes paraneoplásicas, favorece seu prognóstico favorável. É muito importante que os Cirurgiões-dentistas conheçam as mani- 
festações de tais síndromes de modo a identificá-las num menor período e encaminhar esses pacientes a especialista.

\section{REFERÊNCIAS}

1. Herrero C. Bronquiolites obliterante y pênfigo paraneoplásico autoinmune multiorgánico. Arch Bronconeumol 2004;40(5):240-3.

2. Sutton I, Winer JB. The immunopathogenesis of paraneoplastic neurological syndromes. Clin Sci 2002;102:475-86.

3. Goldman L, Ausiello D. Cecil - Tratado de medicina interna. 22. ed. Rio de Janeiro: Elsevier; 2009. p. 1301-9.

4. Rosenfeld MR, Dalmau J. Current therapies for paraneoplastic neurologic syndromes. Curr Treat Potions Neurol 2003;5:69-77.

5. Azulay RD, Azulay DR, Abulafia LA. Sinais malignos na pele versus síndromes paraneoplásicas cutâneas: revisão. An Bras Dermatol 2000;75(5):621-30.

6. Campos FG, Habr-Gama A, Kiss DR, Atui FC, Katayama F, Gama-Rodrigues J. Manifestações extracolônicas da polipose adenomatosa familiar: incidência e impacto na evolução da doença. Arq Gastroenterol 2003;40(2):92-8.

7. Hobert JA, Eng C. PTEN hamartoma tumor syndrome: an overview. Genet Méd 2009;11(10):687-94.

8. Calva D, Howe JR. Hamartomatous polyposis syndromes. Surg Clin North Am 2008;88(4):779-817.

9. Guimarães PB, Branco AA, Carvalho E, Lima FE, Almeida JR, Santos JB, et al. Síndrome de Cowden: relato de um caso. An Bras Dermatol 2002;77(6):711-20.

10. Santos MACG, Nunes AB, Abelin N, Ezabella MCL, Toledo RA, Lourenço Junior D, et al. Rastreamento gênico da neoplasia endócrina múltipla tipo 2: experiência da Unidade de Endocrinologia Genética da USP. Arq Bras Endocrinol Metab 2006;50:7-16.

11. Maia AL, Gross JL, Punales MK. Neoplasia endócrina múltipla tipo 2 . Arq Bras Endocrinol Metab 2005;49(5):725-34.

12. Al-Otibi M, Rutka JT. Neurosurgical implications of neurofibromatosis type I in children. Neurosurg Focusm 2006;19(6):E2.

13. Simonato LE, Ribeiro ACP, Santos CA, Takano RY, Miyahara GI, Furuse TA et al. Neurofibromatose múltipla: acompanhamento clínico e radiográfico de 10 anos. Ciênc Odontol Brás 2006;9(4):92-8.

14. Mansur C, Mansur L, Gonçalves RC, Mansur J, Gamonal AC, Valverde R. Síndrome de Peutz-Jeghers: tratamento da lentiginose oral com laser alexandrita. An Bras Dermatol 2003;78(4):501-5.

15. Auluck A, Suhas S, Pai KM. Multiple odontogenic keratocysts: report of a case. J Can Dent Assoc 2006;72(7):651-6.

16. Díaz-Fernández JM, Cossío PI, Caro RB, Laza LR, García AGP, Pérez JLG. Basal cell nevus syndrome: presentation of six cases and literature review. Med Oral Patol Cir Bucal 2005;1(10):57-66.

17. Shear M. The aggressive nature of the odontogenic keratocyst: is it a benign cystic neoplasm? Part 2: proliferation and genetic studies. Oral Oncol 2002;38(4):323-31.

18. Braverman IM. Skin manifestations of internal malignancy. Clin Geriatric Med 2002;18:1-19.

19. Fam AG. Paraneoplastic rheumatic syndromes. Bailliere"s Clin Rheum 2000;14:515-33. 